\title{
Duodenal Signet Ring Cell Carcinoma in a Celiac Patient
}

\author{
Franco Pisello ${ }^{a}$ Girolamo Geraci ${ }^{a, b} \quad$ Francesco Li Volsi ${ }^{a}$ \\ Francesca Stassi $^{a} \quad$ Giuseppe Modica $^{a} \quad$ Carmelo Sciumè $^{a, b}$ \\ aSection of General and Thoracic Surgery and 'bervice of Surgical Endoscopy, \\ University of Palermo, Palermo, Italy
}

\section{Key Words}

Celiac disease · Duodenal adenocarcinoma $\cdot$ Resection · Surgery · Signet ring cell

\begin{abstract}
Celiac disease results from damage to the small intestinal mucosa due to an inappropriate immune response to a cereal protein. Long-standing or 'refractory' celiac disease is associated with an increased risk of autoimmunity and malignancy. We produced a brief literature review starting from a case of duodenal cancer in a celiac patient. The patient with an history of celiac disease since six months presented with acute manifestation of gastric outlet syndrome. A duodenal stricture was diagnosed at upper gastrointestinal endoscopy and confirmed by abdominal computed tomography. He was successfully treated by segmental duodenal resection. In the resected specimens, the diagnosis was duodenal signet cell adenocarcinoma. 6-month follow-up is uneventful. Primary carcinoma of the duodenum is rare (duodenal adenocarcinoma accounts for less than $0.5 \%$ of all gastrointestinal cancers and $30-45 \%$ of small intestinal cancers). Some patients with duodenal carcinoma are potentially curable by surgery, but conflicting opinions exist on the factors influencing the survival rate and on surgical treatment as the gold standard. Nevertheless, the goal in surgical treatment is to achieve clear margins. At present, surgical resection (pancreaticoduodenectomy or pancreas-sparing duodenal segmental resection) is the only available option for cure of this disease.
\end{abstract}

\section{Introduction}

Celiac disease (CD) results from damage to the small intestinal mucosa due to an inappropriate immune response to a cereal protein. The term 'celiac' derives from the Greek 'koiliakos', meaning 'belly'. The disorder was previously called 'celiac sprue', based on the Dutch word 'sprue', which was used to describe a disease similar to tropical sprue that is characterized by diarrhea, emaciation, aphthous stomatitis, and malabsorption. CD is a common condition that may present at any age after weaning with a spectrum of 
symptoms. Treatment with a strict gluten-free diet is mandatory and leads to a reduced risk of associated complications. Long-standing or 'refractory' $\mathrm{CD}$ is associated with an increased risk of autoimmunity and malignancy. The diagnosis of cancer could be after the diagnosis of $\mathrm{CD}$ or simultaneous (during the same month or at admission) or more frequently before the diagnosis [1]. In 1962, Gough et al. [2] suggested, for the first time, that lymphoma occurs as a complication of CD. An increase in gastrointestinal adenocarcinoma was also found to occur. Carcinoma of the small intestine in association with CD was first reported in 1958 and is now known to be the second most common invasive malignancy after lymphoma.

\section{Case Report}

A celiac (diagnosis 2 years before) 46-year-old woman on a gluten-free diet, without any other past medical history, presented with a six-month history of projectile vomiting, postprandial fullness and $13 \mathrm{~kg}$ weight loss. She proceeded to gastroduodenal endoscopy: the stomach was dilated and revealed retained gastric fluid. In the duodenum a loss of folds, scalloping of folds, a mucosal mosaic pattern and micronodularity in the duodenal bulb were observed. Furthermore, the presence of a stricturing tumor was observed in the third part of the duodenum (fig. 1). A multiple biopsy with large forceps was performed. The biopsy specimens of the lesion showed the typical appearances of CD with total villous atrophy. No sign of tumor was detected. A second gastroduodenal endoscopy was done with duodenal lesion biopsy. Even in this case the specimen histology was negative. Thus, the patient underwent computed tomography, which showed a long segmental stenosis from the third duodenal portion to the duodenal-jejunal junction (fig. 2 ) suggestive of obstructive lesion. No lymph node was observed. The patient proceeded to laparotomy, where a $8 \times 5 \times 1 \mathrm{~cm}$ duodenal tumor was seen close to the duodenal-jejunal flexure, and a segmental duodenal-jejunal resection was performed (fig. 3 ). Histopathology confirmed a stricturing duodenal signet ring adenocarcinoma with clear resection margins, limited to the muscular wall, with histological signs of $\mathrm{CD}$ in the specimen around the tumor (fig. 4). No lymph nodes were detected. A normal gastrografin study was done on the 7th postoperative day before discharge (inpatient day 15). The postoperative course was uneventful. Adjuvant chemotherapy was performed with UFTM protocol (uracil, ftorafur and mitomycin C) and was associated with normalization of CEA and CA 19-9. 6-month follow-up is uneventful (endoscopy and pathological findings confirmed the disappearance of the cancer).

\section{Discussion}

The increased risk of mortality in CD is largely attributable to malignancy [3]. Malignant diseases that are more frequent in patients with CD include non-Hodgkin lymphoma, esophageal and oropharyngeal squamous carcinoma, and small bowel adenocarcinoma [1,4]. Small bowel carcinoma is well recognized in association with long-standing gluten enteropathy, particularly in patients in whom the mucosa remains flat even after appropriate dietary treatment. However, a gluten-free diet is thought to be protective against the development of malignancy in $\mathrm{CD}$, although this might not be the case for the development of non-Hodgkin lymphoma [5, 6]. Primary carcinoma of the duodenum is rare. Duodenal adenocarcinoma accounts for less than $0.5 \%$ of all gastrointestinal cancers and for $30-45 \%$ of small intestinal cancers [7].

The precise prevalence of malignancy in $\mathrm{CD}$ is unknown [8]. Enteropathy-associated $\mathrm{T}$ cell lymphoma occurs in approximately 1 per million population per year in the UK and is rapidly fatal with approximately $20 \%$ survival at 2 years. The risk of duodenal adenocarcinoma is also increased [6]. Patients with CD have a risk of small bowel adenocarcinoma that is about $40-80$ fold greater than that of the general population, but only around $10 \%$ of patients with this tumor are celiac [9-12]. 
Small intestinal adenocarcinomas are rare tumors. The diagnosis of carcinoma can be after the diagnosis of CD or simultaneous (during the same month or at admission) or more frequently before the diagnosis [3]. The development of carcinoma may bring a patient with CD to diagnosis or provoke symptoms in a patient previously well controlled on a gluten-free diet. The diagnostic modalities have evolved over time, from upper gastrointestinal series with small bowel follow-through to computed tomography, ultrasound, and endoscopic biopsy.

Various explanations have been put forward for this increased risk of developing carcinomas [3]. The mucosal damage in CD may make the small intestine more permeable to environmental carcinogens. Known predisposing factors for the development of small intestinal adenocarcinoma include Crohn's disease, adenomatous polyps and Peutz-Jeghers syndrome. These adenocarcinomas have macroscopic and microscopic features similar to adenocarcinoma arising in the colon. Malignancy in CD can be diagnosed by biopsy at endoscopy, but there is no precise histopathological description nor specificity for these carcinomas.

Anemia is the most common presenting feature and is associated with either overt or occult gastrointestinal bleeding [12]. Weight loss with worsening anorexia, nausea, abdominal pain or abdominal mass and small bowel obstruction are other prominent complains. Rarely, a perforated viscera can be the initial complication leading to a cancer diagnosis. Other atypical presentations such as shortness of breath, generalized lymphadenopathy, and neurologic signs and symptoms account for the remainder of clinical manifestations $[12,13]$. Some patients with duodenal carcinoma are potentially curable by surgery [8]. Conflicting opinions exist on the factors influencing the survival rate. A number of investigators stated that $T$ stage, nodal status, degree of differentiation and the use of adjuvant chemoradiation therapy did not influence survival, whereas negative resection margins and tumor site (i.e. first and second portions of the duodenum) are favorable predictors of long-term survival [14]. In contrast, others authors have shown that survival is only dependent on the presence or absence of nodal involvement at presentation $[7,8]$. In fact, Kalamanos et al. found that the presence of lymph node involvement is associated with a truncated survival and node positivity was the only independent negative prognostic factor for survival among patients who underwent resection (N+: 15\% 5-year survival vs. N-: 60\% 5-year survival) [7]. Pericolo et al. observed a median survival of 13 months, with a 35\% 5-year survival [11]. Hurtuk et al. showed that the size of neoplasm is not a determinant of resectability of duodenal carcinoma; on the contrary, he found that small tumors tended to be more aggressive than larger tumors [14]. There are no confirmed statistical data in the literature on the degree of differentiation of neoplasm on the correlation with patient survival $[7,10,14]$. Chemotherapy can be administered after surgical resection, particularly in patients with lymphoma, or as the sole treatment in patients with advanced or inoperable disease.

At present, surgical resection is the only available option for cure of this disease $[15,16]$. Complete resection remains the only option for cure, but this is not always feasible in case of locally advanced tumors or in case of tumors invading the root of the mesentery. The choice of surgical resection depends on the site of the tumor $[17,18]$. Pancreaticoduodenectomy (PD) is the only appropriate operation to achieve a complete resection when the neoplasm is located in the second part of the duodenum, close to the papilla of Vater and the pancreatic head $[19,20]$. For neoplasm located in the first, third or fourth portions of the duodenum, complete resection may be achieved with removal of the affected segment $[7,21]$. With aggressive lymph node dissection, PD for a tumor in the proximal duodenum or pancreas-sparing duodenectomy for a tumor in the distal 
duodenum are the most common surgical treatments for duodenal adenocarcinoma, and they may provide a curative option for these patients [7, 14]. As to the correct approach, some surgeons have suggested that all cancers should be treated by PD [13], citing the principle that regional lymph node dissection is more complete [16]. It has been argued that segmental duodenal resection results in inadequate resection margins and an incomplete regional lymphadenectomy $[9,10]$. On other hand, the segmental resection appears to be equally extensive as PD in terms of clearance of regional lymph node [7]. Thus, as there are not uniform opinions on the surgical management of duodenal adenocarcinoma, and as several follow-up studies suggest that a gluten-free diet protects from cancer development, especially if started during the first years of life, strict adherence to a gluten-free diet seems to be the only possibility of preventing a subset of rare but very aggressive forms of cancer [22].

\section{Conclusion}

Actually, from the review of the literature, numerous are the conflicting opinions about prognostic survival factors in duodenal adenocarcinoma. Ultimately the goal in surgical treatment is to achieve clear margins. Particularly for tumors arising in the third and fourth segment of the duodenum confined to the duodenal wall, complete resection with microscopic negative margins can frequently be accomplished with a segmental duodenal resection that should include removal of the periduodenal lymph node. Otherwise, PD remains the procedure of choice for tumors located in the second portion of the duodenum and for locally advanced distal tumor. In conclusion, all celiac patients with duodenal carcinoma fit for surgery should be given the option of curative treatment by surgical resection regardless of tumor size, tumor invasion, or appearance of positive lymph nodes.

Fig. 1. Duodenal stricturing tumor.

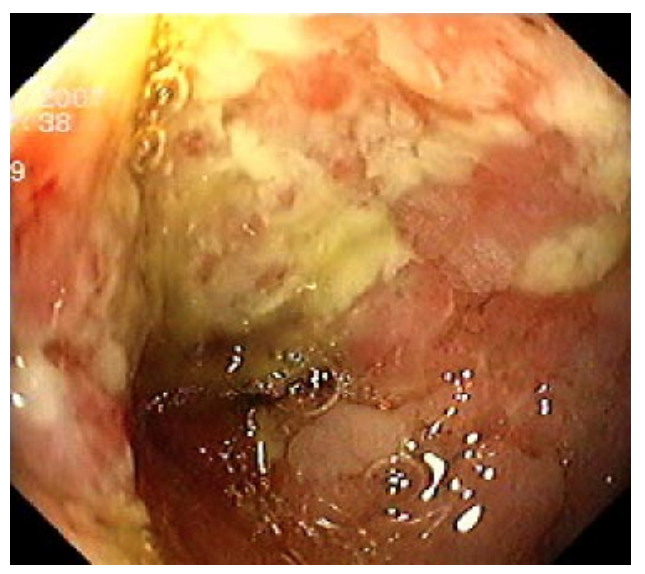




\begin{tabular}{r|l|l|l} 
Case Reports $/ \mathrm{n}$ & $\begin{array}{l}\text { Case Rep Gastroenterol 2009;3:49-55 } \\
\text { D01: 10.1159/000212992 }\end{array}$ & Published online: April 10, 2009 & $\begin{array}{l}\text { 2009 S. Karger AG, Basel } \\
\text { ISSN 1662-0631 } \\
\text { Www.karger.com/crg }\end{array}$ \\
\hline
\end{tabular}

Fig. 2. Computed tomography showing duodenal stricture (circle).

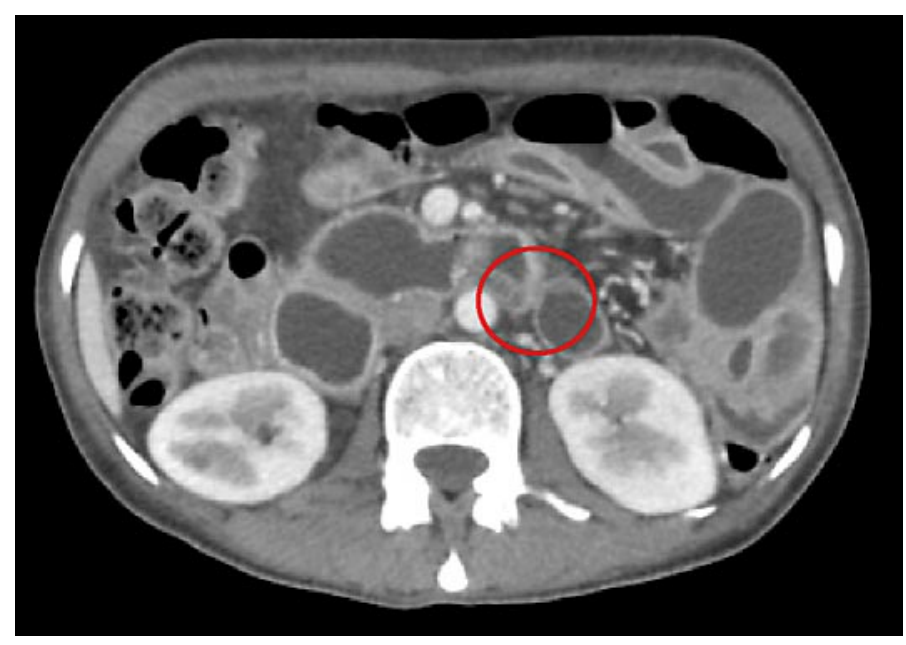

Fig. 3. The stricture in the opened specimen (circle).

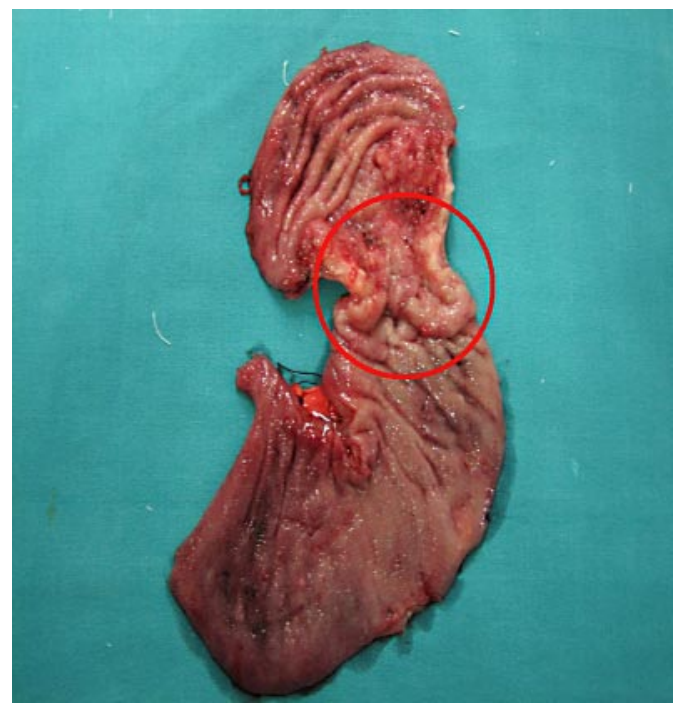




\begin{tabular}{r|l|l|l} 
Case Reports $/ \mathrm{n}$ & $\begin{array}{l}\text { Case Rep Gastroenterol 2009;3:49-55 } \\
\text { D01: 10.1159/000212992 }\end{array}$ & Published online: April 10, 2009 & $\begin{array}{l}\text { 2009 S. Karger AG, Basel } \\
\text { ISSN 1662-0631 } \\
\text { Www.karger.com/crg }\end{array}$ \\
\hline
\end{tabular}

Fig. 4. Histology specimen (H\&E).

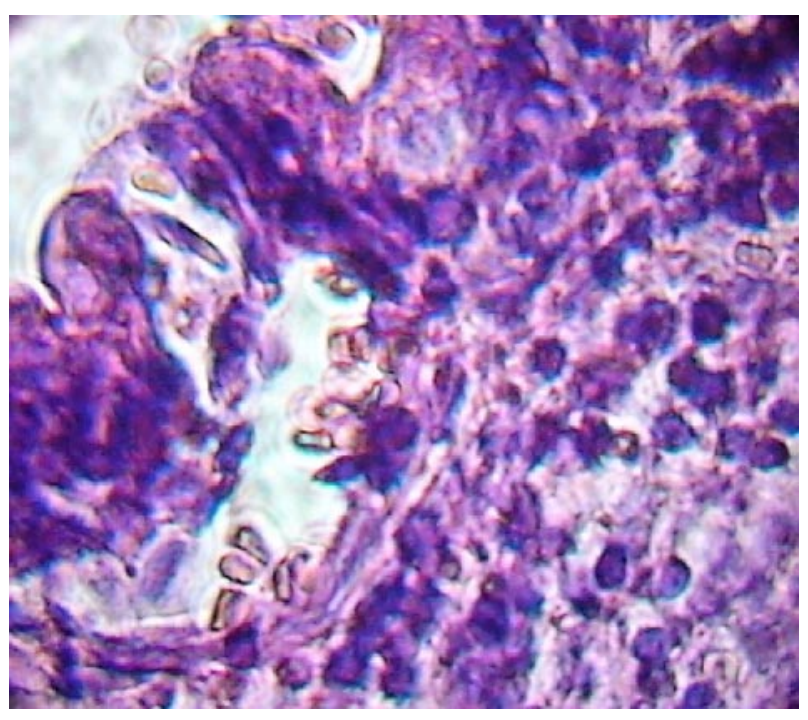




\section{References}

1 Green PHR, Fleischauer AT, Bhagat G, Goyal R, Jabri B, Neugut AI: Risk of malignancy in patients with celiac disease. Am J Med 2003;115:191-195.

-2 Gough KR, Read AE, Naish JM: Intestinal reticulosis as a complication of idiopathic steatorrhoea. Gut 1962;3:232-239.

-3 Corrao G, Corazza GR, Bagnardi V, et al: Mortality in patients with coeliac disease and their relatives: a cohort study. Lancet 2001;358:356-361.

-4 Peters U, Askling J, Gridley G, Ekbom A, Linet M: Causes of death in patients with celiac disease in a population-based Swedish cohort. Arch Intern Med 2003;163:1566-1572.

5 Holmes GK, Prior P, Lane MR, Pope D, Allan RN: Malignancy in coeliac disease effect of a gluten free diet. Gut 1989;30:333-338.

-6 Green PHR, Stavropoulos SN, Panagi SG, Goldstein SL, McMahon DJ, Absan H, Neugut AI: Characteristics of adult celiac disease in the USA: results of a national survey. Am J Gastroenterol 2001;96:126-131.

-7 Kalamanos IG, Bathe OF, Franceschi D, Camarda C, Levi J, Livingstone AS: Extent of resection in the management of duodenal adenocarcinoma. Am J Surg 2000;179:37-41.

8 Holmes GK: Coeliac disease and malignancy. Dig Liver Dis 2002;34:229-237.

-9 Howdle PD, Jalal PK, Holmes GKT, Houlston RS: Primary small bowel malignancy in the UK and its association with coeliac disease. QJM 2003;96:345353.

10 Green PH, Cellier C: Celiac disease. N Engl J Med 2007;357:1731-1743.

11 Pericolo VE, Mangi AA, Aswad B, Bland KI: Gastrointestinal malignancies in patients with celiac sprue. Am J Surg 1998;176:344-347.

12 MacGowan DJL, Hourihane DO, Tanner WA, O’Morain C: Duodeno-jejunal adenocarcinoma as a first presentation of coeliac disease. J Clin Pathol 1996;49:602-604.

13 Brousse N, Meijer JWR: Malignant complications of coeliac disease. Best Pract Res Clin Gastroenterol 2005;19:401-412.

14 Hurtuk MG, Devata S, Brown KM, et al: Should all patients with duodenal adenocarcinoma be considered for aggressive surgical resection? Am J Surg 2007;193:319-325.

15 Sohn TA, Lillemoe KD, Cameron JL, et al: Adenocarcinoma of duodenum: factors influencing long term survival. J Gastrointest Surg 1998;2:79-87.

16 Rose DM, Hochwald SN, Klimstra DS, Brennan MF: Primary duodenal adenocarcinoma: a ten year experience with 79 patients. J Am Coll Surg 1996;83:89-96.

17 Delcore R, Thomas JH, Forster J, Hemreck AS: Improving resectability and survival in patients with primary duodenal carcinoma. Am J Surg 1993;166:626631.

18 Bucher P, Gervaz P, Morel P: Long term results of radical resection for locally advanced duodenal adenocarcinoma. Hepatogastroenterology 2005;52:17271729.

19 Hung FC, Kuo CM, Chuah SK, Kuo CH, Chen YS, Lu SN, Chang Chien CS: Clinical analysis of primary duodenal adenocarcinoma: an 11-year experience. J Gastroenterol Hepatol 2007;22:724-728.

20 Sohn TA, Lillemoe KD, Cameron JL, Pitt HA, Kaufman HS, Hruban RH, Yeo CJ: Adenocarcinoma of the duodenum: factors influencing long-term survival. J Gastrointest Surg 1998;2:79-87.

21 Lai ECS, Doty JE, Irving C, Tompkins RK: Primary adenocarcinoma of the duodenum: analysis of survival. World J Surg 1988;12:695-699.

22 Catassi C, Bearzi I, Holmes GKT: Association of celiac disease and intestinal lymphomas and other cancers. Gastroenterology 2005;128:S79-S86. 